\title{
Winter warming rapidly increases carbon degradation capacities of fungal communities in tundra soil: potential consequences on carbon stability
}

\author{
Jingmin Cheng ${ }^{1}$, Yunfeng Yang ${ }^{1}$, Mengting Yuan ${ }^{2}$, Ziyan Qin ${ }^{3}$, Qun Gao ${ }^{1}$, Liyou $\mathrm{Wu}^{2}$, \\ Zhou Shi ${ }^{2}$, Edward Schuur ${ }^{4}$, James R Cole ${ }^{5}$, James Tiedje ${ }^{5}$, and Jizhong Zhou ${ }^{1}$ \\ ${ }^{1}$ Tsinghua University \\ ${ }^{2}$ University of Oklahoma \\ ${ }^{3}$ Affiliation not available \\ ${ }^{4}$ Northern Arizona University \\ ${ }^{5}$ Michigan State University
}

July 20, 2020

\begin{abstract}
High-latitude tundra ecosystems are increasingly affected by climate warming. As an important fraction of soil microorganisms, fungi play essential roles in carbon (C) degradation, especially the old, chemically recalcitrant C. However, it remains obscure how fungi respond to climate warming and whether fungi, in turn, affect $\mathrm{C}$ stability of tundra. In a two-year winter soil warming experiment of $2{ }^{\circ} \mathrm{C}$ by snow fences, we investigated responses of fungal communities to warming in the active layer of the Alaskan tundra. Although fungal community composition, revealed by $28 \mathrm{~S}$ rRNA gene amplicon sequencing, remained unchanged $(\mathrm{P}>0.05)$, fungal functional gene composition, revealed by a microarray named GeoChip, was altered $(\mathrm{P}<0.05)$. Changes in functional gene composition were linked to winter soil temperature, thaw depth, soil moisture, and gross primary productivity (Canonical Correlation Analysis, $\mathrm{P}<0.05$ ). Specifically, relative abundances of fungal genes encoding invertase, xylose reductase, and vanillin dehydrogenase significantly increased $(\mathrm{P}<0.05)$, indicating higher $\mathrm{C}$ degradation capacities of fungal communities under warming. Accordingly, we detected changes of fungal gene networks under warming, including higher average path distance, lower average clustering coefficient, and lower percentage of negative links, indicating that warming potentially changed fungal interactions. Together, our study revealed higher $\mathrm{C}$ degradation capacities of fungal communities under short-term warming and highlights the potential impacts of fungal communities on mediating tundra ecosystem respiration, and consequently future $\mathrm{C}$ stability of high-latitude tundra.
\end{abstract}

\section{Introduction}

High-latitude tundra is one of the most vulnerable ecosystems to climate warming (Myers-Smith et al., 2015), wherein permafrost thawing and changes of vegetation patterns have been observed during past decades (Schuur, Crummer, Vogel, \& Mack, 2007; Sturm, Racine, \& Tape, 2001; Xue et al., 2016). Given the fact that permafrost soil of high-latitude tundra contains up to half of the global soil carbon (C) storage (Tarnocai et al., 2009), warming-induced permafrost C loss to atmosphere could be one of the most severe concerns for accelerating climate warming by greenhouse gas effects (Natali et al. 2011; Schuur et al. 2009). In a warmer world, vast $\mathrm{C}$ may be released to the atmosphere as a result of stimulated microbial activities to accelerate permafrost $\mathrm{C}$ degradation (Mann et al., 2015; Zhou et al., 2012).

As the major soil $\mathrm{C}$ decomposers, fungi may affect the $\mathrm{C}$ stability of high-latitude tundra considerably (Christiansen et al., 2016). For instance, saprotrophic fungi are important regulators of soil nutrient cycling 
via organic C decomposition, especially lignin (Buckeridge, Banerjee, Siciliano, \& Grogan, 2013; Yuste et al., 2011). In winter, fungi are the largest proportion of soil microbial biomass and predominantly affect wintertime C degradation (Buckeridge et al., 2013; Schadt, Martin, Lipson, \& Schmidt, 2003). Additionally, mycorrhizal fungi form mutually beneficial associations to facilitate the growth of arctic plants, especially those warming-responsive plant species such asSalix spp., and Betula nana (Clemmensen, Michelsen, Jonasson, \& Shaver, 2006), and thus can regulate C stability by affecting primary productivity. Therefore, responses of fungal communities to climate warming would be determinative for the $\mathrm{C}$ fate in tundra ecosystems.

Using PCR-based marker gene sequencing, several in situ field studies have demonstrated that experimental warming changes taxonomic composition and environmental group abundances of fungal communities in tundra soil, with increased diversity of saprotrophic fungi but decreased diversity of ectomycorrhizal fungi (Morgado et al., 2016; Mundra et al., 2016; Semenova et al., 2016). However, such taxonomic information provides little insight into the relationship between fungal functions and ecological processes. Functional gene analysis has been applied to quantify functional genes responsible for key ecosystem processes. The main findings of previous studies (Levy-Booth, Prescott, \& Grayston, 2014; Yergeau, Kang, He, Zhou, \& Kowalchuk, 2007), i.e., close relationships between functional gene abundances and ecosystem processes, have provided important insights on the roles of microbial communities in ecosystem functioning.

In addition to taxonomic composition, it is possible that fungal functional genes, serving as markers of potential functional capacities, are sensitive to climate warming. The justification includes 1) Temperature affects the syntheses of cryoprotective compounds essential for maintaining fungal growth and functions in cold environments (Weinstein, Montiel, \& Johnstone, 2000); 2) Temperature sensitivity of soil heterotrophic respiration (measured as $\mathrm{Q}_{10}$ ) is widespread (Malcolm, Lopez-Gutierrez, Koide, \& Eissenstat, 2008), implying that $\mathrm{C}$ degradation capacities of soil microorganisms including fungi are variable; and 3) Plant litter input would be higher under warming (Rinnan, Michelsen, Baath, \& Jonasson, 2007), which may stimulate fungimediated C degradation.

As the change of functional gene composition can inevitably affect interactions among microbial members, it is important to elucidate complex interactions among microbial functional genes or species containing these genes in order to understand ecosystem functioning (Wu et al., 2016). However, it remains challenging due to myriad members in microbial communities and difficulties in cultivating individual species. In recent years, network analysis has been widely used to reveal potential interactions among co-existing microbial members (Banerjee et al., 2016; Banerjee, Schlaeppi, \& van der Heijden, 2018; de Vries et al., 2018). Accumulating evidence shows that network properties can reflect responses of microbial communities to environmental disturbances (de Vries et al., 2018; De Vries et al., 2012), as drought treatment in grassland mesocosms led to higher connectivity and lower modularity of soil bacterial networks than fungal networks, which suggested lower stability of bacteria than fungi under drought (de Vries et al., 2018).

In the present work, we analyzed the effects of winter warming on fungal communities in the active layer of the Alaskan tundra, via 28S gene amplicon sequencing and GeoChip technologies. Through installing snow fences to increase snow cover thus winter soil temperature, we tested the following hypotheses: 1) Warming would affect fungal community composition and potential interactions; 2) Fungal C degradation capacities, represented by the abundances of $\mathrm{C}$ degradation genes, would be increased by warming; 3) Increased fungal $\mathrm{C}$ degradation capacities could explain the increase of ecosystem respiration $(R$ есо $)$, as recently witnessed in several studies (Liu et al., 2015; Trivedi et al., 2016; Zhao et al., 2014).

\section{Methods \& Materials}

\section{Site description and experimental design}

This study was carried out in Carbon in Permafrost Experimental Heating Research (CiPEHR) site, established in September 2008. This site is a typical moist acidic tundra located in the northern foothills of Interior Alaska (635' $59^{\prime \prime}$ N, $149^{\circ} 13^{\prime} 32^{\prime \prime}$ W), near the Denali National Park and Preserve of Eight Mile Lake. The annual mean temperature of the year $1976-2009$ was $-1.0^{\circ} \mathrm{C}$, with monthly mean temperature ranging from $-16{ }^{\circ} \mathrm{C}$ (December) to $15^{\circ} \mathrm{C}$ (July). The annual mean precipitation of $1976-2009$ was $378 \mathrm{~mm}$. The soil type is 
gelisol, with a 45-65 cm thick organic horizon covered by a mixture of glacial till and loess. The active layer thickness is 50-60 cm. Dominant plant species included the tussock-forming sedge Eriophorum vaginatum (Cyperaceae) and the small deciduous shrub Vaccinium uliginosum (Ericaceae). Other plants included Carex bigelowii(Cyperaceae), bryophytes Pleurozium schreberi (Hylocomiaceae),Sphagnum spp. (Sphagnaceae), and lichens Cladonia spp. (Cladoniaceae).

The experimental soil warming study was initiated in October 2008. A total of 6 snow fences $(1.5 \mathrm{~m}$ tall $\times 8 \mathrm{~m}$ long) were established and arranged into 3 blocks, which was $\sim 100 \mathrm{~m}$ apart to mitigate small-scale spatial variability. For each snow fence, the warmed plot was located at the leeward side with $5 \mathrm{~m}$ distance from the fence, and the paired control plot was located at the windward side with 8-14 m distance from the fence. Snow fences increased soil temperature via trapping insulating layers of snow in the leeward side. For example, snow fences led to a threefold increase in snow depth of warmed plots in 2009 (1.35 m in warmed plots versus $0.38 \mathrm{~m}$ in control plots) (Natali et al., 2011). Different from traditional snow fence experiments, both snow and snow fences were removed before snowmelt to ensure that soil hydrology, light conditions, and plant phenology were not affected by extra snow. On March 8-15 of 2010, extra snow in warmed plots was shoveled to ensure comparable snow cover depth between warmed and control plots. Snow fences were removed at the time of snow removal to avoid shading of plots during the growing season (Natali, Eag, \& Rubin, 2012; Natali et al., 2011). Snow removal allowed this experiment to focus on the effects of soil warming.

\section{Plant survey and ecosystem $C$ flow measurements}

Plants were identified at the species level and classified as shrubs, graminoids, bryophytes, and lichens. Plant biomass and net primary productivity (NPP) of each plant group were measured by a point-frame method (Walker, 1996), based on previously developed allometric equations (Schuur et al., 2007).

Soil temperature at 15-25 cm depth in winter and soil moisture in the growing season were measured in situ every 30 minutes using constantan-copper thermocouples with CR1000 data loggers (Campbell Scientific, Logan, UT, USA). Thaw depth, which is the thickness of unfrozen soil in the growing season, was measured weekly using a metal depth probe. In the growing season, net ecosystem exchange (NEE) and ecosystem respiration $\left(R_{\text {eco }}\right)$ were measured using an automated $\mathrm{CO}_{2}$ flux system. Gross primary productivity (GPP) was calculated as the sum of NEE and $R$ eco of the growing season. Winter $R$ есо was modeled from the measured $\mathrm{CO}_{2}$ flux data of March-April 2009 using an infrared gas analyzer, following detailed description of the modeling methodology shown in the Appendix of a previous paper (Natali, Schuur, Webb, Pries, \& Crummer, 2014). In brief, an exponential equation between winter $R$ eco and soil temperature was developed, i.e., winter $R$ есо $=R \times \exp ^{(\beta \times \mathrm{T} \varsigma)}$, where $R$ is basal respiration, $\beta$ is the rate of respiration change, and Ts is soil temperature at $20 \mathrm{~cm}$ depth. For CiPEHR site, parameter values estimated for this model were $R$ $=0.47(0.03)$ and $\beta=0.18(0.06)$. This model was validated by comparing the simulation results with all observed $R$ eco values available from flux sites $\left(R^{2}=0.70, P<0.001\right)$. Since no photosynthesis occurs in winter, winter $R$ ecomainly represents heterotrophic respiration. $R$ ecoin this study is annual $R$ eco that is a sum of winter $R$ есо and growing season $R$ есо. The period ranges of GPP and NEE data were May 2010 - September 2010. The period ranges of other environmental data, including $R$ eco, soil temperature, soil moisture, and thaw depth, were October 2009-September 2010.

\section{Soil sampling and biogeochemical measurements}

Soil samples were collected in early May of 2010. To dismiss within-plot heterogeneity, we collected a relatively large soil core $(>2 \mathrm{Kg})$ from each plot. A total of 12 soil cores at $15-25 \mathrm{~cm}$ depth from warmed plots and their paired control plots were collected using electric drills and were transported to the laboratory on ice. In the lab, we divided each sample into two parts using a sterile saw: one for soil DNA extraction (stored at $-80{ }^{\circ} \mathrm{C}$ ); the other for soil biogeochemical measurements (stored at $4{ }^{\circ} \mathrm{C}$ ), including bulk density, labile carbon pool (LCP, mainly polysaccharides and cellulose), recalcitrant carbon pool (RCP, mainly lignin), total organic carbon (TOC), soil nitrogen, $\mathrm{NH}_{4}{ }^{+}-\mathrm{N}$, and $\mathrm{NO}_{3}{ }^{-} \mathrm{N}$. Soil bulk density was calculated as its dry mass (oven-drying at $60 \mathrm{deg}$ for three days) divided by its frozen volume. A two-step hydrolysis procedure 
separated LCP and RCP. LCP was quantified by a Shimadzu TOC-V CPH PC-Controlled TOC analyzer (Shimadzu Corporation, Tokyo, Japan). RCP was quantified by a PerkinElmer Optima 2000DV ICP-OES spectrometer (PerkinElmer Inc., Waltham, MA, USA) (Rovira \& Vallejo, 2002). $\mathrm{NH}_{4}{ }^{+}-\mathrm{N}$ and $\mathrm{NO}_{3}{ }^{-}-\mathrm{N}$ were measured using anion (AG 1-X8, 20-50 mesh) and cation (AG 50W-X8, 20-50 mesh) exchange bags (Biorad, Hercules, CA, USA). In each sampling plot, a cation bag and an anion bag were placed at a depth of $10 \mathrm{~cm}$ during May-September 2010. Then samples in the bags were collected, and inorganic nitrogen components were extracted in the $0.1 \mathrm{M} \mathrm{HCl} / 2.0 \mathrm{M} \mathrm{NaCl}$ solution for an hour in the lab and analyzed on an Astoria Analyzer (Astoria-Pacific Int., Clackamas, OR, USA).

\section{Soil DNA extraction}

DNA was extracted from $5 \mathrm{~g}$ of soil samples stored at $-80 \mathrm{deg}$, following the instruction of PowerMax Soil DNA Isolation Kit (MoBio Laboratories, Carlsbad, CA, USA). DNA quality was assessed via a NanoDrop ND-1000 Spectrophotometer (NanoDrop Technologies Inc., Wilmington, DE, USA), based on UV spectrometry absorbance ratios at wavelengths of $260 \mathrm{~nm} / 280 \mathrm{~nm}$ and $260 \mathrm{~nm} / 230 \mathrm{~nm}$. DNA concentration was measured by PicoGreen using a FLUOstar OPTIMA fluorescence plate reader (BMG Labtech, Jena, Germany).

Pyrosequencing of $28 S$ rRNA gene amplicons

$28 \mathrm{~S}$ rRNA gene was applied to investigate fungal taxonomy in this study. After combining with a single sample-specific 8-mer tag sequence separated by a 2-bp spacer sequence, the primers LR0R (5'ACCCGCTGAACTTAAGC-3') and LR3 (5'-CCGTGTTTCAAGACGGG-3') were applied to amplify the D1-D2 region of $28 \mathrm{~S}$ rRNA gene, which generated a gene amplicon of about $650 \mathrm{bp}$. The $100 \mu \mathrm{L}$ PCR system was composed of $50 \mathrm{mM} \mathrm{KCl}, 10 \mathrm{mM}$ Tris- $\mathrm{HCl}$ at $\mathrm{pH}$ of $8.3,0.1 \%$ Triton $\mathrm{X}-100,2.5 \mathrm{mM} \mathrm{MgCl}_{2}$, $200 \mu \mathrm{M}$ dNTPs (Invitrogen Life Technologies, Carlsbad, CA, USA), 5 units of Taqpolymerase, $0.1 \mu \mathrm{g}$ BSA (New England Biolabs Inc., Ipswich, MA, USA), $0.4 \mu \mathrm{M}$ each primer and $12.5 \mathrm{ng}$ DNA template. PCR thermocycling conditions were as follows: $3 \mathrm{~min}$ at $94{ }^{\circ} \mathrm{C}$ for initialization, followed by 35 cycles of 1 min at $94{ }^{\circ} \mathrm{C}$ for denaturation, 45 secs at $53{ }^{\circ} \mathrm{C}$ for annealing, 1 min at $72{ }^{\circ} \mathrm{C}$ for extension, and finally 15 min at $72{ }^{\circ} \mathrm{C}$ before maintained at $4{ }^{\circ} \mathrm{C}$. For each sample, five to ten PCR reactions were performed. PCR products were combined and purified by agarose gel electrophoresis, and then collected with QIAquick Gel Extraction Kit (Qiagen, Venlo, Netherlands). PCR products were quantified by PicoGreen using a FLUOstar Optima (BMG Labtech, Jena, Germany). Equimolar uniquely-tagged amplicons from each sample were then combined into one library. Tags separated raw sequences via the function "Split by tag" of the IEG Galaxy pipeline (http://zhoulab5.rccc.ou.edu:8080). They were further cleaned via LUCY based on the following thresholds: maximum average error at 0.01 , maximum error at the ends at 0.01 , minimum score at 21 , window size at 50 , minimum length at 200 , and allowable ambiguous base number (' $\mathrm{N}$ ') at 10 . Only sequences with no ' $\mathrm{N}$ ' were accepted and were clustered into operational taxonomic units (OTUs) using UCLUST at the $97 \%$ identity. OTU singletons were removed and OTUs annotation was performed by the RDP Classifier with the latest Fungal LSU training set 11 (http://rdp.cme.msu.edu/classifier/classifier.jsp) at the $50 \%$ confidence interval. We used raw OTU abundance in the following data analyses.

\section{GeoChip 4.2 hybridization}

Fungal functional genes were accessed by GeoChip 4.2 (Roche NimbleGen Inc., Madison, WI, USA), which is a functional microarray containing more than 107,950 oligonucleotide probes of 792 bacterial, archaeal and fungal genes associated with $\mathrm{C}$, nitrogen $(\mathrm{N})$, phosphorus $(\mathrm{P})$ and sulfur $(\mathrm{S})$ cycling, stress, virulence, energy process, to name a few. These oligonucleotide probes are designed from functional gene sequences of microbial organisms with known taxonomy in the NCBI database (He et al., 2007). Before hybridization, $1 \mu \mathrm{g}$ of purified DNA was labeled with the fluorescent dye Cy3. After overnight hybridization, unbound DNA was removed. Then GeoChip was scanned by a NimbleGen MS 200 Microarray Scanner (Roche, Basel, Switzerland) at $532 \mathrm{~nm}$ and $635 \mathrm{~nm}$. Probes with signal-to-noise ratio lower than 2 were considered to be unreliable and hence removed. The normalized signal intensity of each detected probe was calculated by dividing total signal intensity by each detected probe and log-transformed. 


\section{Network construction}

To detect warming effects on potential fungal interactions, we used functional gene data to construct functional molecule ecological networks (fMENs) for control and warmed samples separately, via the pipeline of Molecular Ecological Network Analyses (MENA) (http://ieg4.rccc.ou.edu/mena/) (Deng et al., 2012). Only functional genes detected in all six biological replicates were included to ensure network reliability. To compare topological characteristics between control and warmed networks, we chose the same threshold of 0.98 during network construction, which refers to the Spearman's correlation coefficients between pairwise OTUs. Network modules, which are groups of nodes that highly connected within the group but less connected outside the group, were separated by the fast-greedy modularity optimization. Network topological characteristics were calculated via MENA, including total nodes, total edges, average connectivity (node degree), average clustering coefficient, average path distance, and modularity. Network randomization (a total of 100 random networks) was performed via MENA. To test whether fMENs of control and warmed samples have typical properties of biological networks (e.g., small-world, hierarchy, modularity), network topological characteristics were compared with their corresponding 100 random networks. To test statistical differences of fMENs between control and warmed samples, we performed two-tailed Student's $t$-tests by taking their network topological characteristics as averages and standard deviations of their corresponding 100 random networks as standard deviations (Wu et al., 2016). Cytoscape (version 3.5.1) was used for network visualization. Some network scores (e.g., connectivity) were used to identify putative key genes/species that have large influences in maintaining community structure and function, despite that species identities can be inaccurate owing to horizontal gene transfer. To select network key genes, we set thresholds based on within-module connectivity $(\mathrm{Zi})$ and among-module connectivity (Pi) of nodes: $\mathrm{Zi}$ [?] 2.5 and $\mathrm{Pi}$ [?] 0.62 for network hubs, $\mathrm{Zi}$ [?] 2.5 and $\mathrm{Pi}<0.62$ for module hubs, $\mathrm{Zi}<2.5$ and $\mathrm{Pi}$ [?] 0.62 for connectors, $\mathrm{Zi}<2.5$ and $\mathrm{Pi}<0.62$ for peripherals (Guimera \& Amaral, 2005). Previous studies have shown that network key genes/species were inclined to be more responsive to environmental changes than others (Wu et al., 2016). Therefore, we checked whether the connectivity of network key genes was linked to warming-induced changes in environmental factors by performing partial Mantel tests between the matrix of connectivity of network key genes and the matrix of environmental factors.

\section{Statistical analyses}

Statistical analyses were carried out via $\mathrm{R}$ software (version 3.4.2). Diversity indices (i.e., Shannon-Wiener index and Richness) and Plelou's evenness of functional genes and OTUs were calculated. Two-tailed Student'st -tests on diversity indices, relative abundances of each functional gene and gene category, and relative abundance of each OTU and higher taxonomic levels were performed between warmed and control samples. $P$-values were adjusted by the Benjamini \& Hochberg $(\mathrm{BH})$ correction with the false discovery rate of 0.10 . The multi-response permutation procedure (MRPP) and analysis of similarity (ANOSIM) were performed via mrpp and anosim functions in veganpackage in $\mathrm{R}$ to examine overall differences in functional gene composition or OTU composition between warmed and control samples. If significant differences were found, then the similarity percentage (SIMPER) analysis, via the simper function in the veganpackage in R, was applied to reveal which functional genes or OTUs caused the differences as well as their contributions. The principal coordinate analysis $(\mathrm{PCoA})$ was performed to visualize the overall composition of functional genes and OTUs. The canonical correlation analysis (CCA) and the variation partitioning analysis (VPA), via the cca function in vegan package in $\mathrm{R}$, were performed to reveal which environmental factors were closely linked to differences between control and warmed samples and their contributions. We only selected environmental factors with the variance inflation factor (VIF) $<20$ in the CCA model and tested the overall significance of the CCA model by ANOVA. Relationships between $R$ eco and relative abundances of fungal functional genes for $\mathrm{C}$ degradation were examined by linear regression.

\section{Results}

Environmental factors

Snow fences and resulting thicker snow cover significantly increased winter soil temperature from $-5.6 \pm 0.6{ }^{\circ} \mathrm{C}$ 
to $-3.7 \pm 0.9{ }^{\circ} \mathrm{C}$ (Table S1, $P<0.01$ ), and exerted legacy effects on soil and plants in the subsequent growing season. For instance, soil moisture significantly increased from $47.8 \pm 4.9 \%$ to $52.7 \pm 2.0 \%(P=0.03)$, and thaw depth significantly increased from $35.3 \pm 0.8 \mathrm{~cm}$ to $38.4 \pm 2.6 \mathrm{~cm}(P=0.03)$. Gross primary productivity (GPP) significantly increased from $394.5 \pm 7.0 \mathrm{~g} \mathrm{~m}^{-2}$ to $514.7 \pm 7.4 \mathrm{~g} \mathrm{~m}^{-2}(P=0.01)$, mainly attributed to the increase in graminoid biomass $\left(146.7 \pm 38.7 \mathrm{~g} \mathrm{~m}^{-2}\right.$ in control plots vs. $231.0 \pm 86.5 \mathrm{~g} \mathrm{~m}^{-2}$ in warmed plots, $P$ $=0.05)$. As high plant biomass usually leads to more plant respiration, $R$ eco, the sum of aboveground plant and soil respiration, was significantly enhanced from $363.3 \pm 3.7 \mathrm{~g} \mathrm{~m}^{-2}$ to $449.2 \pm 4.4 \mathrm{~g} \mathrm{~m}^{-2}(P<0.01)$. There were no significant changes of soil $\mathrm{C}$ and $\mathrm{N}$ pools, including LCP $(P=0.94), \mathrm{RCP}(P=0.94), \mathrm{NH}_{4}{ }^{+}-\mathrm{N}(P$ $=0.47)$, and $\mathrm{NO}_{3}{ }^{-} \mathrm{N}(P=0.59)$.

Fungal taxonomic composition

The $\mathrm{C} 1$ and $\mathrm{C} 2$ samples of control plots were not saturated in sequence depths (less than 10,000 sequences, based on the rarefaction curves in Fig. S1), probably due to technical problems of DNA sequencing. Therefore, they were discarded for data analyses. After resampling of raw $28 \mathrm{~S}$ rRNA gene reads, a total of 126,050 highquality sequence reads were generated and were clustered into 991 OTUs at the $97 \%$ identity.Ascomycota $(70.66 \pm 11.80 \%)$ was the dominant phylum, followed by Basidiomycota $(14.21 \pm 10.19 \%)$, Chytridiomycota $(0.51 \pm 0.64 \%)$ and Blastocladiomycota $(<0.01 \%)$. Those OTUs were assigned to 135 genera and the most abundant genera included Kriegeria $(9.14 \pm 9.64 \%)$, Hyaloscypha $(6.63 \pm 5.41 \%)$, Collophora $(3.43 \pm 6.50 \%)$, Mol-

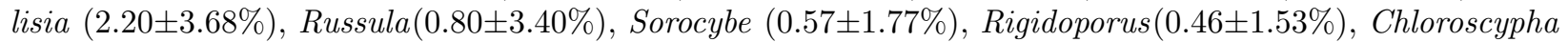
$(0.45 \pm 0.78 \%)$, Hymenoscyphus $(0.41 \pm 0.61 \%)$ and Crinula $(0.40 \pm 1.00 \%)$. The fungal genera were further classified into 6 ecological groups based on their roles in ecosystems (Tedersoo et al., 2014) - saprotrophs (57\%), plant pathogens (24\%), ectomycorrhizal fungi (6\%), animal parasites (5\%), mycoparasites (2\%) and mycobionts (6\%), among a total of the 135 genera. However, soil warming did not change the overall fungal community composition, reputing part of our first hypothesis (Table 1 \& Fig. S2a). Additionally, no differences in diversity and environmental group abundances were found between warmed and control samples (Table S3).

\section{Fungal functional gene composition}

A total of 2,590 probes of 82 fungal functional genes responsible for nutrient cycling, stress, energy processes, and virulence were detected. In line with our first hypothesis, we found that warming altered the overall functional gene composition significantly (Table $1, P<0.05$ ), which was further verified by the PCoA plot (Fig. S2b). Therefore, we performed the SIMPER analysis to identify major functional genes responsible for the differences. A total of 12 functional genes had significant contributions (Table 2, $P<0.05$ ), which were associated with $\mathrm{C}$ degradation (i.e., genes encoding cellobiase, xylanase, glyoxal oxidase, metalloprotease, phospholipase A2, vanillin dehydrogenase, xylose reductase, invertase), S cycling (i.e., genes encoding sulfate transporter and PAPS reductase), P utilization (i.e., the gene encoding phytase) and stress tolerance (i.e., the gene encoding superoxide dismutase).

In line with our second hypothesis, 3 out of a total of 53 fungal $\mathrm{C}$ degradation genes showed significantly $(P<0.05)$ higher relative abundances under warming, which encode invertase for sucrose degradation (increased by $16.7 \%$ ), xylose reductase for hemicellulose degradation (increased by $231.62 \%$ ), and vanillin dehydrogenase for lignin-derived aromatics degradation (increased by $47.64 \%$ ) (Fig. 1). The gene encoding phytase for $\mathrm{P}$ utilization was also significantly increased by $11.37 \%(P<0.05)$. Additionally, a total of 30 oligonucleotide probes of $\mathrm{C}$ degradation genes were only detected in warmed samples (Table $\mathrm{S} 2$ ).

\section{Network topological characteristics}

Using functional gene data, we generated fMENs for control and warmed samples. Both networks were scalefree (power-law $\mathrm{R}^{2}>0.85$ ), and possessed other typical properties of biological networks such as small-world and modularity (Table 3). In line with Hypothesis 1, the fMEN of warmed samples had significantly different topological characteristics with the fMEN of control $(P<0.001)$. The average path distance of warmed samples (18.718) was significantly higher than that of control $(10.325)(P<0.001)$, whereas the average clustering coefficient of warmed samples $(0.298)$ was significantly lower than that of control $(0.329)(P<$ 
0.001). A lower percentage of negative links was found in the fMEN of warmed samples (19.78\%) than in control (36.32\%) (Fig. 2 \& Table 3$)$.

Based on Zi and Pi values of both networks, 12 genes were identified as key genes (9 module hubs and 3 connectors) of warmed samples, while 14 genes were identified as key genes (11 module hubs and 3 connectors) of control samples (Fig. 2 \& Table S4). A much higher percentage of key genes were associated with C degradation in warmed samples $(91.7 \%, 11$ out of 12 genes) than in control $(64.3 \%, 9$ out of 14 genes) (Table S4). Partial Mantel tests revealed that thaw depth was significantly linked to network connectivity of key genes $(P<0.01)$.

Linkages between environmental factors and fungal functional gene composition

The increase of winter soil temperature and associated changes of soil hydrologic conditions (including soil moisture and thaw depth) and GPP in the growing season significantly contributed to the differences of functional gene composition (CCA model: $\mathrm{F}=1.57, P=0.01$ ) (Fig. 3a). Those factors explained $47.25 \%$ of the differences, among which winter soil temperature explained $10.35 \%$, soil hydrologic conditions explained $20.10 \%$, and GPP explained $12.48 \%$ (VPA, Fig. 3b).

Linkages between fungal $C$ degradation genes and $R$ eco

In line with the third hypothesis, $R$ eco had positively linear regressions with the relative abundances of fungal $\mathrm{C}$ degradation genes encoding xylose reductase $\left(R^{2}=0.56, P<0.01\right)$, vanillin dehydrogenase $\left(R^{2}=0.44, P\right.$ $=0.02)$, glyoxal oxidase $\left(R^{2}=0.32, P=0.03\right)$, and aspartate protease $\left(R^{2}=0.33, P=0.03\right)$ (Fig. 4).

\section{Discussion}

Understanding fungal response to climate warming is important for revealing their roles in nutrient cycling processes and evaluating the ecological consequences of climate warming on high-latitude tundra. In this study, we hypothesized that climate warming would affect fungal community composition and potential interactions. Our hypotheses were partially upheld: fungal functional gene composition and potential interactions among genes/species were significantly altered, whereas fungal community composition was unchanged (Table 1 \& Fig. 2). Different responses of functional gene composition and community composition were similar to the findings of a previous warming study in a tall-grass prairie ecosystem (Cheng et al., 2017), suggesting that GeoChip is more sensitive for detecting subtle changes in functional genes. Due to horizontal gene transfer among microbial species, species identities detected in GeoChip do not reliably represent phylogenetic species in environmental samples. However, if both sequencing and GeoChip data point to the same species, the chance of disconnection between sequencing and GeoChip is slim. For example, we detected both functional genes and OTUs belonging toHypocrea in GeoChip data and amplicon sequencing data. Similar to the overall changes of fungal composition change, we found significant increases in gene abundances from Hypocrea (e.g., the genes encoding endochitinase, exopolygalacturonase, and xylanase) $(P<$ $0.05)$, whereas no changes of OTUs from this genus. Nonetheless, the lack of detectable changes in fungal community composition should be interpreted with caution because $28 \mathrm{~S}$ rRNA gene has a relatively low taxonomic resolution (Brown, Rigdon-Huss, \& Jumpponen, 2014), which might fail to detect subtle changes in fine taxonomic levels (Hultman et al., 2015).

Ascomycota was the dominant fungal phylum in our study and other studies conducted in sedge-occupied tussock tundra (Christiansen et al., 2016; Deslippe, Hartmann, Simard, \& Mohn, 2012; Timling, Walker, Nusbaum, Lennon, \& Taylor, 2014). However, this phylum was less dominant in shrub-occupied tundra (Wallenstein, McMahon, \& Schimel, 2007), indicating that vegetation pattern is probably closely related to fungal community composition. Climate warming has caused vegetation shifts in the tundra, with diminishing sedges and bryophytes but expanding shrubs and trees (Fraser, Lantz, Olthof, Kokelj, \& Sims, 2014; Sturm et al., 2001). Considering the potential relationship between fungi and plants, it is likely that dominant fungi in high-latitude tundra will shift accompanying the shrub expansion.

The increase in fungal $\mathrm{C}$ degradation capacities, based on higher relative abundances of functional genes encoding invertase, xylose reductase, and vanillin dehydrogenase (Fig. 1), might imply that fungi-mediated 
$\mathrm{C}$ degradation was accelerated under warming. Those genes are associated with the degradation of complex plant-derived saccharides (Culleton, Mckie, \& de Vries, 2013), probably resulting from higher plant productivity (Table S1). Moreover, higher vanillin dehydrogenase gene abundance might result from the "priming effect," i.e., labile C input can stimulate recalcitrant C degradation (de Graaff, Classen, Castro, \& Schadt, 2010; Mau, Dijkstra, Schwartz, Koch, \& Hungate, 2018). Warming-induced increases of fungal C degradation capacities were also found in other ecosystems including grasslands (Cheng et al., 2017), subtropical freshwater wetlands (Wang et al., 2012), deserts (Weber et al., 2011), showing a consistent response pattern of fungal communities across ecosystems. For example, in the biological soil crusts of a desert, soil warming increased the abundance of fungal functional gene $c b h I$, which encodes cellobiohydrolase for cellulose degradation (Weber et al., 2011).

Higher average path distance but lower average clustering coefficient of the warmed fMEN (Table 3) suggested that the complexity of potential interactions decreased under warming. As the percentage of negative links could represent competition within community members (Fuhrman, 2009), a lower percentage of negative links in warmed fMEN concurred with higher soil nutrient availability that alleviates resource competition (Banerjee et al., 2016). Higher nutrient availability appears to stimulate C degradation, as almost all key genes, the most important members in maintaining network structure and strongly influence community stability and functions (Banerjee et al., 2018; Shi et al., 2016), in warmed fMEN were associated with C degradation (Table S4). However, it is important to bear in mind a caveat that most networks cannot distinguish true ecological interactions based on positive or negative correlations between nodes since it remains largely intractable to analyze in situ microbial interaction experimentally in most communities of natural environments (Faust \& Raes, 2012). When interpreting networks in ecological terms, topological properties (e.g., average node connectivity, average path length, clustering coefficient, and modularity), which reflect whole-network changes, could be more reliable.

Legacy effects of winter warming included increases in thaw depth, soil moisture, and GPP in the growing season (Table S1). The increase of thaw depth, a sign of permafrost degradation, was also observed in previous experimental warming studies using snow fences (Hinkel \& Hurd, 2006; Nowinski, Taneva, Trumbore, \& Welker, 2010). Since we excluded snow addition effects on soil hydrological conditions by removing snow before melting, the most likely cause of soil moisture increase was ice-wedge melting in permafrost (Liljedahl et al., 2016). Soil temperature, soil moisture, thaw depth, and GPP imposed the strongest influence on fungal functional gene composition (Fig. 3), suggesting that they were very important in affecting fungal functional capacities. Oxygen availability could be affected by soil hydrology and temperature, which is shown to change species diversity, ecological functions, and survival of most aerobic fungi (Wang et al., 2012; Zak \& Kling, 2006).

Permafrost thawing increases the potential of old $\mathrm{C}$ degradation, leading to stronger heterotrophic respiration and $\mathrm{CO}_{2}$ emission (Nowinski et al., 2010; Schuur et al., 2009). Consistently, we found a significant warminginduced increase in $R$ eco (Table S1 \& Fig. 4), primarily resulting from the increase in winter $R$ eco that mainly represents heterotrophic respiration (by $103.2 \%, P<0.05$, Table S1). Our winter $R$ eco data were derived from a site-specific model that assumes winter $R$ ecoincreases with soil temperature exponentially, which is commonly used when simulating the temperature dependence of heterotrophic soil respiration. The model fitted in situ measured data well $\left(R^{2}=0.70, P<0.001\right)$, which was consistent with observations elsewhere (Tuomi, Vanhala, Karhu, Fritze, \& Liski, 2008).

Increased $R$ eco shared positive regressions with fungal functional genes for $\mathrm{C}$ degradation (Fig. 4), suggesting that fungal functional capacities in $\mathrm{C}$ degradation might be very important in mediating $R$ eco, and thus the C stability of tundra ecosystems. According to the central dogma, DNA has to be transcribed into RNA and translated into protein before displaying enzymatic activity, which is the missing link in our study since enzyme activities were not measured. However, a large number of papers have justified the strong, positive relationship between enzyme activities and abundances of their encoding genes (Blackwood, Waldrop, Zak, \& Sinsabaugh, 2007; Fan, Li, Wakelin, Yu, \& Liang, 2012; Trivedi et al., 2016). Notably, the positive correlations between $R$ eco and fungal functional genes should be interpreted with caution since GPP was 
also increased by warming (Table S1). Therefore, the increase of $R$ eco could be explained in terms of the increased photosynthesis and corresponding increased respiration of new photosynthate. Additionally, higher bacterial $\mathrm{C}$ degradation capacities under warming conditions at this site have been previously documented (Xue et al., 2016), which could also account for the $R$ eco increase. Therefore, future studies that distinguish plant respiration and heterotrophic soil respiration are needed.

\section{Concluding Remarks}

This study shows that winter warming rapidly alters fungal functional gene composition and potential fungal interactions in Alaskan tundra soil, which are closely linked to the changes of soil hydrological conditions and plant productivity. Higher fungal $\mathrm{C}$ degradation capacities under warming suggest positive feedback of fungal communities to a warmer climate because an increase in $R$ ecois observed, signifying the potential importance of fungi in de-stabilizing tundra soil $\mathrm{C}$ storage. Although it is uncertain whether these conclusions are ubiquitous in other arctic tundra ecosystems due to the limited sampling size and small-scale spatial variability of this study, it represents an important step forward to understand the fungal functional potentials changed by warming. Overall, this study demonstrates fungal community vulnerability to climate warming and provides new insights into the fungi-mediated $\mathrm{C}$ storage in tundra soil. Therefore, incorporating fungi into current Earth system models may help predict the future fate of global C storage.

\section{References}

Banerjee, S., Kirkby, C. A., Schmutter, D., Bissett, A., Kirkegaard, J. A., \& Richardson, A. E. (2016). Network analysis reveals functional redundancy and keystone taxa amongst bacterial and fungal communities during organic matter decomposition in an arable soil. Soil Biology 83 Biochemistry, 97 , 188-198.

Banerjee, S., Schlaeppi, K., \& van der Heijden, M. G. A. (2018). Keystone taxa as drivers of microbiome structure and functioning. Nature Reviews Microbiology, 16 (9), 567-576.

Blackwood, C. B., Waldrop, M. P., Zak, D. R., \& Sinsabaugh, R. L. (2007). Molecular analysis of fungal communities and laccase genes in decomposing litter reveals differences among forest types but no impact of nitrogen deposition. Environmental Microbiology, 9 (5), 1306-1316.

Brown, S. P., Rigdon-Huss, A. R., \& Jumpponen, A. (2014). Analyses of ITS and LSU gene regions provide congruent results on fungal community responses. Fungal Ecology, 9 , 65-68.

Buckeridge, K. M., Banerjee, S., Siciliano, S. D., \& Grogan, P. (2013). The seasonal pattern of soil microbial community structure in mesic low arctic tundra. Soil Biology $\& 3$ Biochemistry, 65 (65), 338-347.

Cheng, L., Zhang, N. F., Yuan, M. T., Xiao, J., Qin, Y. J., Deng, Y., . . . Zhou, J. Z. (2017). Warming enhances old organic carbon decomposition through altering functional microbial communities. The Isme Journal, 11 (8), 1825-1835.

Christiansen, C. T., Haugwitz, M. S., Prieme, A., Nielsen, C. S., Elberling, B., Michelsen, A., . . . Blok, D. (2016). Enhanced summer warming reduces fungal decomposer diversity and litter mass loss more strongly in dry than in wet tundra. Global Change Biology, 23 (1), 406.

Clemmensen, K. E., Michelsen, A., Jonasson, S., \& Shaver, G. R. (2006). Increased ectomycorrhizal fungal abundance after long-term fertilization and warming of two arctic tundra ecosystems. New Phytologist, 171 (2), 391-404.

Culleton, H., Mckie, V., \& de Vries, R. P. (2013). Physiological and molecular aspects of degradation of plant polysaccharides by fungi: What have we learned from Aspergillus? Biotechnology Journal, 8 (8), 884-U822.

de Graaff, M. A., Classen, A. T., Castro, H. F., \& Schadt, C. W. (2010). Labile soil carbon inputs mediate the soil microbial community composition and plant residue decomposition rates. New Phytologist, 188 (4), $1055-1064$. 
de Vries, F. T., Griffiths, R. I., Bailey, M., Craig, H., Girlanda, M., Gweon, H. S., . . . Bardgett, R. D. (2018). Soil bacterial networks are less stable under drought than fungal networks. Nature Communications, 9, 3033 .

De Vries, F. T., Liiri, M. E., Bjornlund, L., Bowker, M. A., Christensen, S., Setala, H. M., \& Bardgett, R. D. (2012). Land use alters the resistance and resilience of soil food webs to drought.Nature Climate Change, $2(4), 276-280$.

Deng, Y., Jiang, Y. H., Yang, Y. F., He, Z. L., Luo, F., \& Zhou, J. Z. (2012). Molecular ecological network analyses. Bmc Bioinformatics, 13 (1), 113.

Deslippe, J. R., Hartmann, M., Simard, S. W., \& Mohn, W. W. (2012). Long-term warming alters the composition of Arctic soil microbial communities. Fems Microbiology Ecology, 82 (2), 303-315.

Fan, F. L., Li, Z. J., Wakelin, S. A., Yu, W. T., \& Liang, Y. C. (2012). Mineral fertilizer alters cellulolytic community structure and suppresses soil cellobiohydrolase activity in a long-term fertilization experiment. Soil Biology \& Biochemistry, 55, 70-77.

Faust, K., \& Raes, J. (2012). Microbial interactions: from networks to models. Nature Reviews Microbiology, $10(8), 538-550$.

Fraser, R. H., Lantz, T. C., Olthof, I., Kokelj, S. V., \& Sims, R. A. (2014). Warming-induced shrub expansion and lichen decline in the western Canadian Arctic. Ecosystems, 17 (7), 1151-1168.

Fuhrman, J. A. (2009). Microbial community structure and its functional implications. Nature, 459 (7244), 193-199.

Guimera, R., \& Amaral, L. A. N. (2005). Functional cartography of complex metabolic networks. Nature, 433 (7028), 895-900.

He, Z., Gentry, T. J., Schadt, C. W., Wu, L., Liebich, J., Chong, S. C., . . . Zhou, J. (2007). GeoChip: a comprehensive microarray for investigating biogeochemical, ecological and environmental processes. The Isme Journal, 1,67 .

Hinkel, K. M., \& Hurd, J. K. (2006). Permafrost destabilization and thermokarst following snow fence installation, Barrow, Alaska, USA.Arctic Antarctic and Alpine Research, 38 (4), 530-539.

Hultman, J., Waldrop, M. P., Mackelprang, R., David, M. M., Mcfarland, J., Blazewicz, S. J., . . . Shah, M. B. (2015). Multi-omics of permafrost, active layer and thermokarst bog soil microbiomes.Nature, 521 (7551), 208.

Levy-Booth, D. J., Prescott, C. E., \& Grayston, S. J. (2014). Microbial functional genes involved in nitrogen fixation, nitrification and denitrification in forest ecosystems. Soil Biology 83 Biochemistry, 75 , 11-25.

Liljedahl, A. K., Boike, J., Daanen, R. P., Fedorov, A. N., Frost, G. V., Grosse, G., . . . Zona, D. (2016). Pan-Arctic ice-wedge degradation in warming permafrost and its influence on tundra hydrology.Nature Geoscience, 9 (4), 312-318.

Liu, S., Wang, F., Xue, K., Sun, B., Zhang, Y., He, Z., . . . Yang, Y. (2015). The interactive effects of soil transplant into colder regions and cropping on soil microbiology and biogeochemistry.Environmental Microbiology, 17 (3), 566-576.

Malcolm, G. M., Lopez-Gutierrez, J. C., Koide, R. T., \& Eissenstat, D. M. (2008). Acclimation to temperature and temperature sensitivity of metabolism by ectomycorrhizal fungi. Global Change Biology, 14 (5), 1169-1180.

Mann, P. J., Eglinton, T. I., Mcintyre, C. P., Zimov, N., Davydova, A., Vonk, J. E., . . . Spencer, R. G. M. (2015). Utilization of ancient permafrost carbon in headwaters of Arctic fluvial networks. Nature Communications, 6 , 7856 . 
Mau, R. L., Dijkstra, P., Schwartz, E., Koch, B. J., \& Hungate, B. A. (2018). Warming induced changes in soil carbon and nitrogen influence priming responses in four ecosystems. Applied Soil Ecology, 124, 110-116.

Morgado, L. N., Semenova, T. A., Welker, J. M., Walker, M. D., Smets, E., \& Geml, J. (2016). Long-term increase in snow depth leads to compositional changes in arctic ectomycorrhizal fungal communities. Global Change Biology, 22 (9), 3080-3096.

Mundra, S., Halvorsen, R., Kauserud, H., Bahram, M., Tedersoo, L., Elberling, B., . . . Eidesen, P. B. (2016). Ectomycorrhizal and saprotrophic fungi respond differently to long-term experimentally increased snow depth in the High Arctic. Microbiologyopen, 5 (5), 856-869.

Myers-Smith, I. H., Elmendorf, S. C., Beck, P. S. A., Wilmking, M., Hallinger, M., Blok, D., . . . Vellend, M. (2015). Climate sensitivity of shrub growth across the tundra biome. Nature Climate Change, 5 , 887-891.

Natali, S. M., Eag, S., \& Rubin, R. L. (2012). Increased plant productivity in Alaskan tundra as a result of experimental warming of soil and permafrost. Journal of Ecology, 100 (2), 488-498.

Natali, S. M., Schuur, E. A. G., Trucco, C., Pries, C. E. H., Crummer, K. G., \& Lopez, A. F. B. (2011). Effects of experimental warming of air, soil and permafrost on carbon balance in Alaskan tundra.Global Change Biology, 17 (3), 1394-1407.

Natali, S. M., Schuur, E. A. G., Webb, E. E., Pries, C. E. H., \& Crummer, K. G. (2014). Permafrost degradation stimulates carbon loss from experimentally warmed tundra. Ecology, 95 (3), 602-608.

Nowinski, N. S., Taneva, L., Trumbore, S. E., \& Welker, J. M. (2010). Decomposition of old organic matter as a result of deeper active layers in a snow depth manipulation experiment. Oecologia, 163 (3), 785-792.

Rinnan, R., Michelsen, A., Baath, E., \& Jonasson, S. (2007). Mineralization and carbon turnover in subarctic heath soil as affected by warming and additional litter. Soil Biology 83 Biochemistry, 39 (12), 3014-3023.

Rovira, P., \& Vallejo, V. R. (2002). Labile and recalcitrant pools of carbon and nitrogen in organic matter decomposing at different depths in soil: an acid hydrolysis approach. Geoderma, 107 (1-2), 109-141.

Schadt, C. W., Martin, A. P., Lipson, D. A., \& Schmidt, S. K. (2003). Seasonal dynamics of previously unknown fungal lineages in tundra soils.Science, 301 (5638), 1359-1361.

Schuur, E. A. G., Crummer, K. G., Vogel, J. G., \& Mack, M. C. (2007). Plant species composition and productivity following permafrost thaw and thermokarst in Alaskan tundra. Ecosystems, 10 (2), 280-292.

Schuur, E. A. G., Vogel, J. G., Crummer, K. G., Lee, H., Sickman, J. O., \& Osterkamp, T. E. (2009). The effect of permafrost thaw on old carbon release and net carbon exchange from tundra. Nature, 459 (7246), 556-559.

Semenova, T. A., Morgado, L. N., Welker, J. M., Walker, M. D., Smets, E., \& Geml, J. (2016). Compositional and functional shifts in arctic fungal communities in response to experimentally increased snow depth.Soil Biology \&3 Biochemistry, 100 , 201-209.

Shi, S. J., Nuccio, E. E., Shi, Z. J., He, Z. L., Zhou, J. Z., \& Firestone, M. K. (2016). The interconnected rhizosphere: High network complexity dominates rhizosphere assemblages. Ecology Letters, 19 (8), 926-936.

Sturm, M., Racine, C., \& Tape, K. (2001). Climate change - Increasing shrub abundance in the Arctic. Nature, 411 (6837), 546-547.

Tarnocai, C., Canadell, J. G., Schuur, E. A. G., Kuhry, P., Mazhitova, G., \& Zimov, S. (2009). Soil organic carbon pools in the northern circumpolar permafrost region. Global Biogeochemical Cycles, 23 , GB2023.

Tedersoo, L., Bahram, M., Polme, S., Koljalg, U., Yorou, N. S., Wijesundera, R., . . . Abarenkov, K. (2014). Global diversity and geography of soil fungi. Science, 346 (6213), 1256688. 
Timling, I., Walker, D. A., Nusbaum, C., Lennon, N. J., \& Taylor, D. L. (2014). Rich and cold: diversity, distribution and drivers of fungal communities in patterned-ground ecosystems of the North American Arctic. Molecular Ecology, 23 (13), 3258-3272.

Trivedi, P., Delgado-Baquerizo, M., Trivedi, C., Hu, H. W., Anderson, I. C., Jeffries, T. C., . . . Singh, B. K. (2016). Microbial regulation of the soil carbon cycle: evidence from gene-enzyme relationships. The Isme Journal, 10 (11), 2593-2604.

Tuomi, M., Vanhala, P., Karhu, K., Fritze, H., \& Liski, J. (2008). Heterotrophic soil respiration - comparison of different models describing its temperature dependence. Ecological Modelling, 211 (1-2), 182-190.

Walker, M. (1996). Community baseline measurements for ITEX studies (2nd edn ed.). Copenhagen: Danish Polar Centre.

Wallenstein, M. D., McMahon, S., \& Schimel, J. (2007). Bacterial and fungal community structure in Arctic tundra tussock and shrub soils.Fems Microbiology Ecology, 59 (2), 428-435.

Wang, H., He, Z., Lu, Z., Zhou, J., Van Nostrand, J. D., Xu, X., \& Zhang, Z. (2012). Genetic linkage of soil carbon pools and microbial functions in subtropical freshwater wetlands in response to experimental warming. Applied and Environmental Microbiology, 78 (21), 7652-7661.

Weber, C. F., Zak, D. R., Hungate, B. A., Jackson, R. B., Vilgalys, R., Evans, R. D., . . . Kuske, C. R. (2011). Responses of soil cellulolytic fungal communities to elevated atmospheric $\mathrm{CO}_{2}$ are complex and variable across five ecosystems. Environmental Microbiology, 13 (10), 2778-2793.

Weinstein, R. N., Montiel, P. O., \& Johnstone, K. (2000). Influence of growth temperature on lipid and soluble carbohydrate synthesis by fungi isolated from fellfield soil in the maritime Antarctic. Mycologia, 92 (2), 222-229.

Wu, L., Yang, Y., Chen, S., Zhao, M., Zhu, Z., Yang, S., . . . Zhou, J. (2016). Long-term successional dynamics of microbial association networks in anaerobic digestion processes. Water Research, 104, 1-10.

Xue, K., Yuan, M. M., Zhou, J. S., Qin, Y., Deng, Y., Cheng, L., . . . Bracho, R. (2016). Tundra soil carbon is vulnerable to rapid microbial decomposition under climate warming. Nature Climate Change, 6 , 595-600.

Yergeau, E., Kang, S., He, Z., Zhou, J., \& Kowalchuk, G. A. (2007). Functional microarray analysis of nitrogen and carbon cycling genes across an Antarctic latitudinal transect. The Isme Journal, 1 (2), 163179.

Yuste, J. C., Penuelas, J., Estiarte, M., Garciamas, J., Mattana, S., Ogaya, R., . . . Sardans, J. (2011). Drought-resistant fungi control soil organic matter decomposition and its response to temperature.Global Change Biology, 17 (3), 1475-1486.

Zak, D. R., \& Kling, G. W. (2006). Microbial community composition and function across an arctic tundra landscape. Ecology, 87 (7), 1659-1670.

Zhao, M., Xue, K., Wang, F., Liu, S., Bai, S., Sun, B., . . . Yang, Y. (2014). Microbial mediation of biogeochemical cycles revealed by simulation of global changes with soil transplant and cropping. The Isme Journal, 8 (10), 2045-2055.

Zhou, J. Z., Xue, K., Xie, J. P., Deng, Y., Wu, L. Y., Cheng, X. H., . . . Luo, Y. Q. (2012). Microbial mediation of carbon-cycle feedbacks to climate warming. Nature Climate Change, 2 (2), 106-110.

\section{Acknowledgments}

We thank three anonymous reviewers and the editor for constructive comments and suggestions to make this paper greatly improved. This study is supported by the Second Tibetan Plateau Scientific Expedition and Research (STEP) program (2019QZKK0503), the National Science Foundation of China (41877048 and 
41825016), US Department of Energy, Office of Science, Genomic Science Program under Award Numbers DE-SC0004601 and DE-SC0010715, the NSF LTER program, and the Office of the Vice President for Research at the University of Oklahoma. The authors declare no conflict of interest.

\section{Authors' Contributions}

JZ, ES, JRC, and JT conceived the ideas and designed methodology; MY, ZS, and LW collected the data; MY did sequencing and GeoChip hybridization; JC and QG analyzed the data; JC and YY wrote the first draft of the manuscript. All authors contributed to the manuscript and gave final approval for publication.

\section{Data Accessibility}

All data used in this manuscript have been uploaded. GeoChip raw and normalized signal intensities can be found in Gene Expression Omnibus (GEO) database by the accession number GSE127899. 28S rRNA gene sequencing data can be found in Sequence Read Archive (SRA) database by the project number PRJNA525959. All the environmental data are available online (LTER Network Data Portal, https://portal.lternet.edu/nis/home.jsp).

Figures and Tables

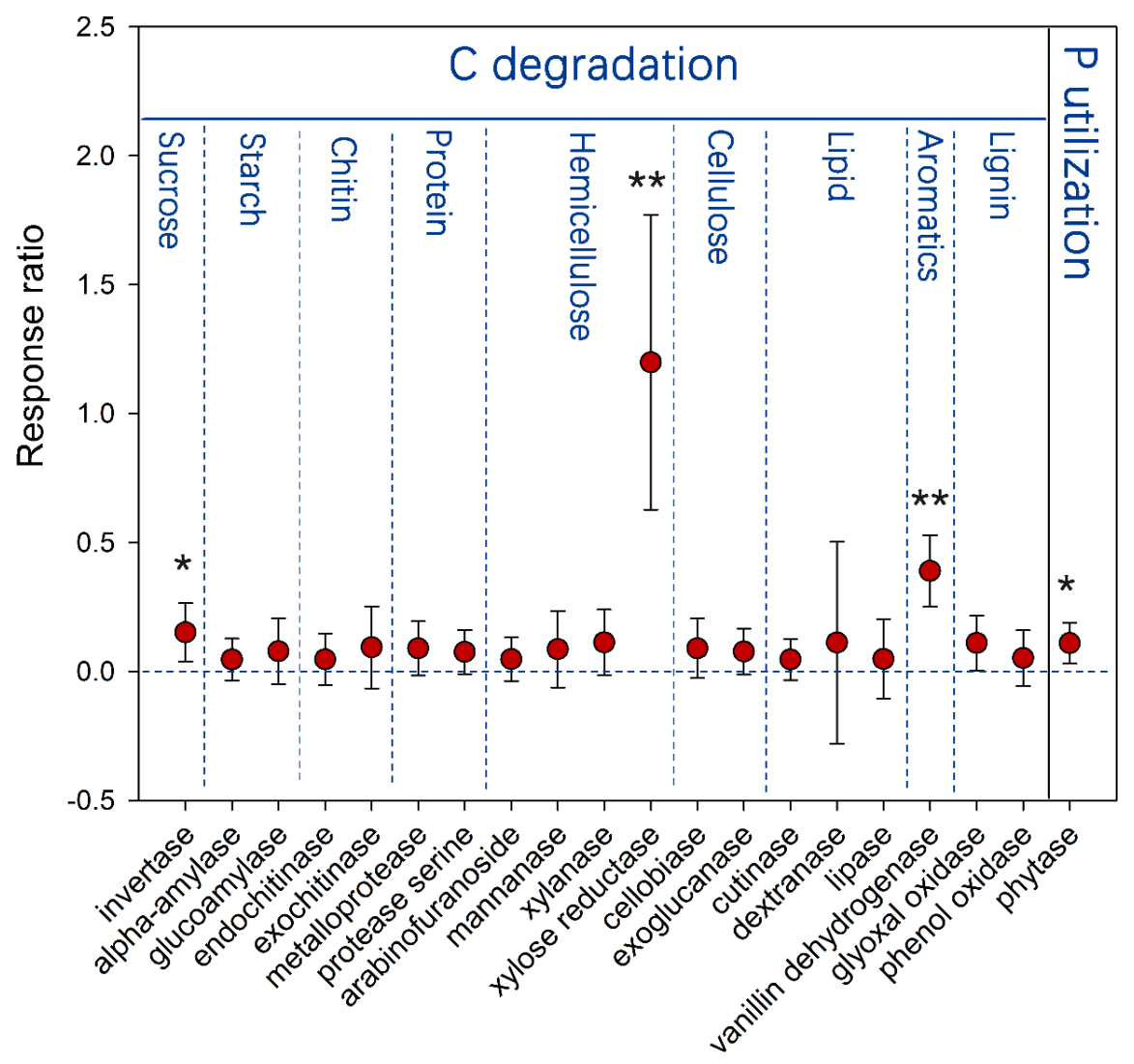

Figure 1. Winter warming increased the relative abundances of fungal functional genes for $\mathrm{C}$ degradation and $\mathrm{P}$ utilization. Response ratios show significant increases of genes encoding xylose reductase, vanillin dehydrogenase, invertase, and phytase (indicated by ${ }^{* *}$ for $P<0.01$ and ${ }^{*}$ for $P<0.05$ ). $\mathrm{C}$ substrates are arranged in the order from labile $\mathrm{C}$ to recalcitrant C. Error bars indicate $95 \%$ confidence intervals of differences of functional gene data between warmed and control samples. 


\section{a}

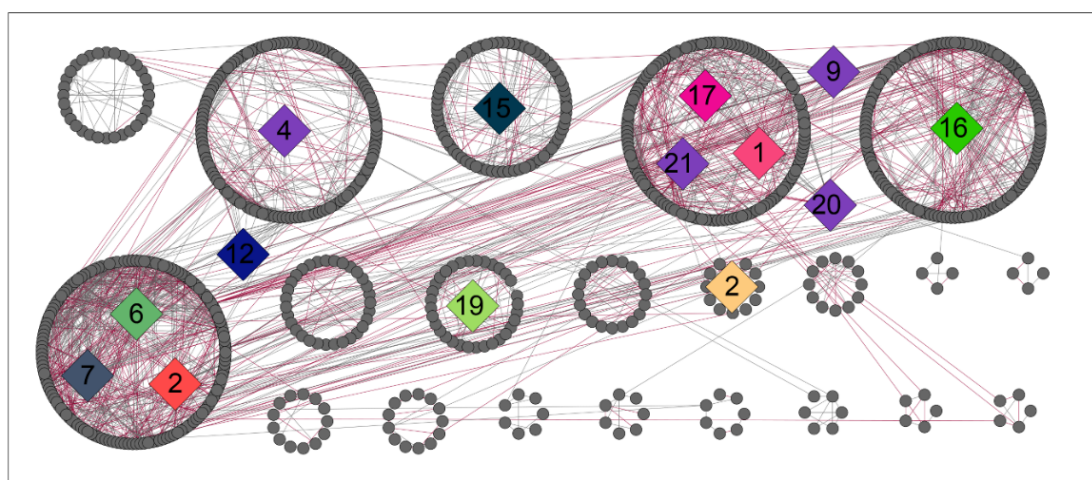

b

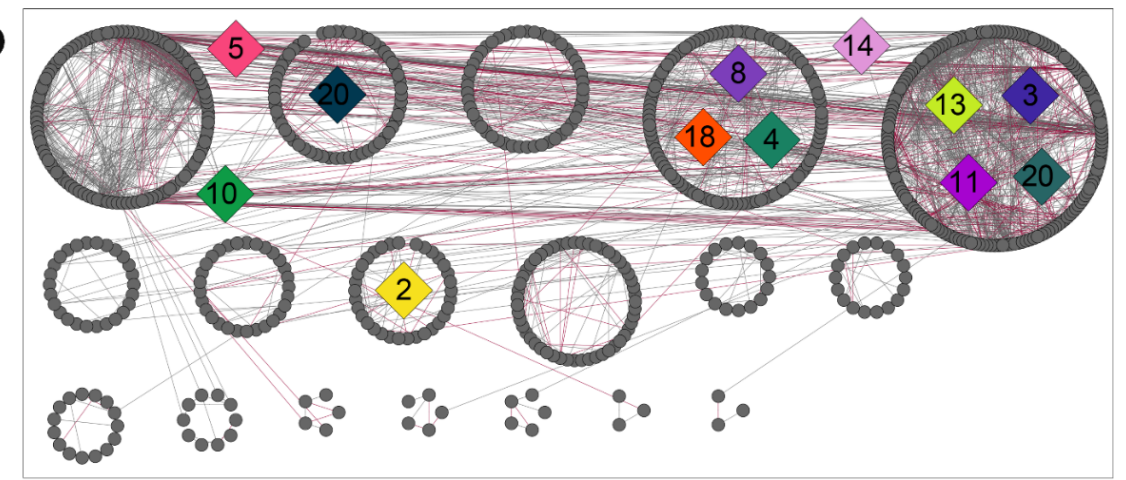

$\square$ manganese peroxidas
mycelial catalase
nitrate reductase
pectate lyase
phenol oxidase
phospholipase A2
phospholipase B
phospholipase D
serine protease
urease

$\begin{array}{ll}2 & \text { Aspergillus clavatus } \\ 3 & \text { Aspergillus oryzae } \\ 4 & \text { Aspergillus terreus } \\ 5 & \text { Aureobasidium } \mathrm{sp} . \\ 6 & \text { Chaetomium globosum } \\ 7 & \text { Coprinopsis cinerea } \\ 8 & \text { Coriolopsis sp. } \\ 9 & \text { Lentinus sp. } \\ 10 & \text { Leptosphaeria } \mathrm{sp} . \\ 11 & \text { Malassezia globosa }\end{array}$

$\begin{array}{ll}12 & \text { Moniliophthora perniciosa } \\ 13 & \text { Neurospora crassa } \\ 14 & \text { Penicillium chrysogenum } \\ 15 & \text { Phanerochaete } \mathrm{sp} . \\ 16 & \text { Pichia pastoris } \\ 17 & \text { Podospora anserina } \\ 18 & \text { Pyrenophora tritici-repentis } \\ 19 & \text { Talaromyces stipitatus } \\ 20 & \text { Trametes sp. } \\ 21 & \text { Uncinocarpus reesii }\end{array}$

Figure 2. Winter warming changes topological characteristics and key genes of functional molecule ecological networks (fMENs):(a) the fMEN of control samples; (b) the fMEN of warmed samples. Each dot or diamond represents a node (fungal functional gene), and each line represents an edge (potential interaction). Networks are separated into modules by using the greedy modularity optimization method and shown as separate circles. Diamond nodes represent key genes of fMENs. Diamond nodes inside modules represent module hubs. Diamond nodes outside modules represent connectors. Different colors of diamond nodes represent different functional genes, and the number marked on each diamond node represents fungal species containing the functional gene. Red lines represent negative links, and black lines represent positive links. 

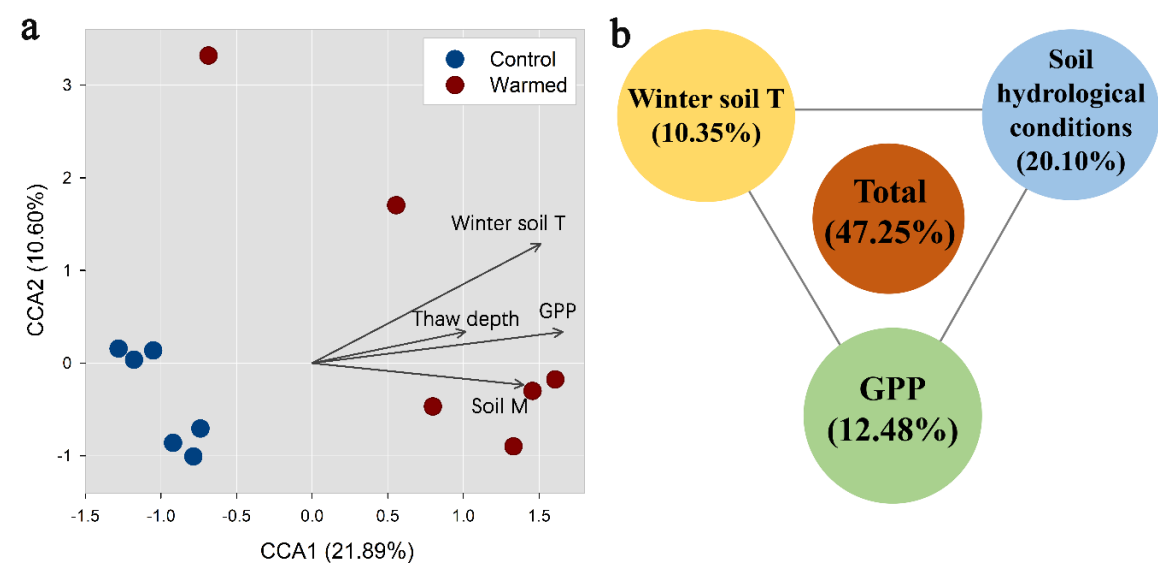

Figure 3. (a) Winter soil temperature (winter soil T), thaw depth, soil moisture (soil M) and gross primary productivity (GPP) are linked to fungal functional gene composition, as revealed by the canonical correlation analysis (CCA); (b) The variation partitioning analysis (VPA) shows explanatory percentages of environmental factors to fungal functional gene composition.
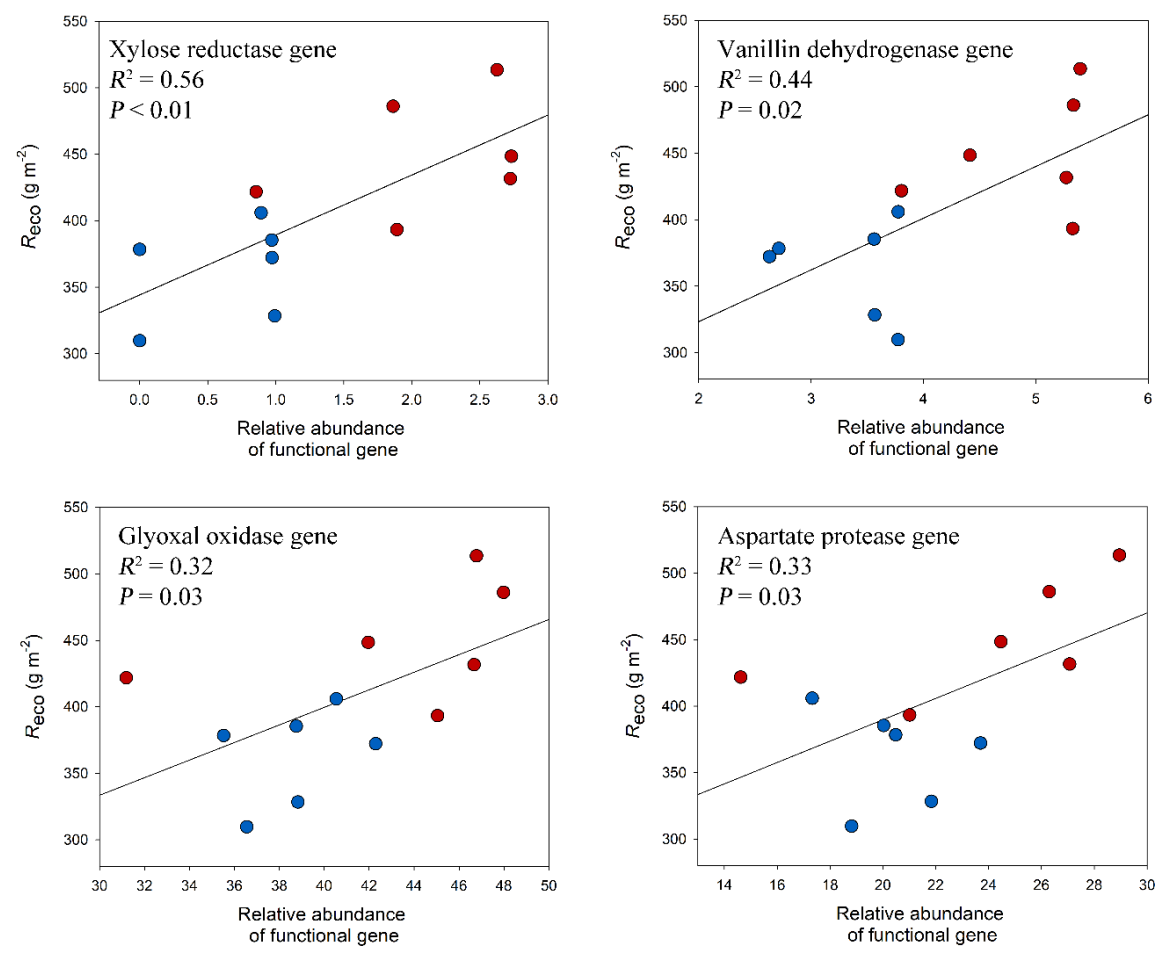

Figure 4. Significant linear regressions between ecosystem respiration $(R$ eco $)$ and relative abundances of fungal functional genes encoding xylose reductase, vanillin dehydrogenase, glyoxal oxidase, and aspartate protease.

Table 1. Results of the multi-response permutation procedure (MRPP) and analysis of similarity (ANOSIM) based on three distance algorithms. Bold values represent $P<0.05$. 


\begin{tabular}{llllllll}
\hline Distance method & MRPP & MRPP & MRPP & MRPP & ANOSIM & ANOSIM & ANOSI \\
& Functional genes & Functional genes & OTUs & OTUs & Functional genes & Functional genes & OTUs \\
& $\delta$ & $P$ & $\delta$ & $P$ & R & $P$ & R \\
Bray-Curtis & 0.11 & $\mathbf{0 . 0 3}$ & 0.75 & 0.64 & 0.32 & $\mathbf{0 . 0 1}$ & -0.18 \\
Euclidean & 17.74 & $\mathbf{0 . 0 2}$ & 5008 & 0.59 & 0.37 & $<\mathbf{0 . 0 1}$ & -0.15 \\
Horn & 0.08 & $\mathbf{0 . 0 2}$ & 0.72 & 0.64 & 0.35 & $<\mathbf{0 . 0 1}$ & -0.13 \\
\hline
\end{tabular}

Table 2. The similarity percentage (SIMPER) analysis reveals genes with significant contributions $(P<$ $0.05)$ to the differences of functional gene composition between control and warmed samples.

\begin{tabular}{llll}
\hline Gene product & Functional process of the gene product & Contribution (\%) & $P$ \\
\hline Cellobiase & C degradation (Cellulose) & 4.97 & 0.04 \\
Sulfate transporter & S transportation & 2.93 & 0.03 \\
Xylanase & C degradation (Hemicellulose) & 2.51 & 0.03 \\
Glyoxal oxidase & C degradation (Lignin) & 2.42 & 0.03 \\
Metalloprotease & C degradation (Protein) & 2.01 & 0.03 \\
Phospholipase A2 & C degradation (Phospholipids) & 1.75 & 0.02 \\
Phytase & P utilization & 1.50 & 0.01 \\
PAPS reductase & S assimilation & 0.77 & 0.04 \\
Superoxide dismutase & Stress tolerance & 0.59 & 0.04 \\
Vanillin dehydrogenase & C degradation (Aromatics) & 0.53 & $<0.01$ \\
Xylose reductase & C degradation (Hemicellulose) & 0.50 & 0.01 \\
Invertase & C degradation (Sucrose) & 0.38 & 0.03 \\
\hline
\end{tabular}

Table 3. Topological characteristics of functional molecule ecological networks (fMENs) of control and warmed samples and their corresponding random networks. Bold values represent $P<0.001$

\begin{tabular}{lll}
\hline Network topological characteristics & Control & Warmed \\
\hline fMENs of control and warmed samples & & \\
Threshold & 0.98 & 0.98 \\
Total nodes & 1211 & 1122 \\
Total edges & 3009 & 2862 \\
$\mathrm{R}^{2}$ of power-law & 0.855 & 0.877 \\
Average connectivity & 4.969 & 5.102 \\
Average clustering coefficient & $\mathbf{0 . 3 2 9}$ & $\mathbf{0 . 2 9 8}$ \\
Average path distance & $\mathbf{1 0 . 3 2 5}$ & $\mathbf{1 8 . 7 1 8}$ \\
Modularity & $\mathbf{0 . 7 7 8}$ & $\mathbf{0 . 7 0 3}$ \\
Negative interactions & $36.32 \%$ & $19.78 \%$ \\
Random networks & & \\
Average clustering coefficient & $0.009 \pm 0.002$ & $0.022 \pm 0.003$ \\
Average path distance & $4.235 \pm 0.022$ & $3.948 \pm 0.030$ \\
Modularity & $0.437 \pm 0.004$ & $0.417 \pm 0.003$ \\
\hline
\end{tabular}

